\title{
Strategies for Agent-based Decision Optimization for Smart Energy Solutions Adoption
}

\author{
Mario Chauca, Dr. \\ Universidad Ricardo Palma, Perú, mario.chauca@urp.edu.pe
}

\begin{abstract}
Agent-based simulation of the decision-making process for the adoption of smart energy solutions can provide evidence for smart energy solution providers to decide on a business strategy that results in the best adoption rate. The adoption rate of smart energy solutions is important to achieving climate goals, such as the Danish goal of 100\% renewable electricity production by 2030. This document shows how agent-based simulation can be used to investigate the process of decision-making for the adoption of smart energy solutions. The study investigates a case of the adoption of a demand response program by Danish commercial greenhouse producers. The simulation developed in AnyLogic generates an adoption and information curve for the producer. The results provide the maximum monetary cost to achieve a $50 \%$ adoption rate in 5 years.
\end{abstract}

Keywords-Agent-based simulation, Smart energy solutions, Decision making, Innovation adoption.

\section{INTRODUCTION}

The Paris Agreement was made with 181 parties [1] in 2015. The Paris Agreement is about keeping a global temperature rise below $2{ }^{\circ} \mathrm{C}$ above pre-industrial levels and to pursue efforts to limit the temperature increase even further to $1.5^{\circ} \mathrm{C}$ in this century [2]. Denmark takes part in this agreement and has designed its own climate goals in accordance with the Paris Agreement. Denmark's Energy Agreement from 2018 states that by $2030,100 \%$ of electricity production comes from renewable energy sources [3]. A long-term objective of the agreement is for Denmark to be a low-emission society in 2050, independent of fossil fuels $[3,4]$. In the future, energy use should be more efficient as well as more intelligent that there is a balance between the consumption and the fluctuating renewable energy sources.

In order to achieve this goal, the entire energy system must be designed to integrate fluctuating energy generation and consumers have to adopt technologies that allow them to use energy more flexible [5]. One way to do so is to invest heavily in expanding the energy infrastructure. Another and cheaper way is to use Demand Response (DR), which allows the use of energy flexibility at the consumption side.

However, introducing new smart energy solutions in the energy system does not mean the solutions will be adopted and utilized by consumers, and many factors affect the decision making of adopting and implementing a new solution.
One factor is the adoption rate that depends on the barriers for adopting an innovation and the triggers which are used to overcome these barriers [6]. A great tool for studying decisionmaking is agent-based modeling which can simulate consumer behavior in a specific environment. By simulating consumer's adoption behaviors, the solution providers can make strategies that promote and increase the adoption rate of an innovative solution.

Therefore, this paper aims to investigate the adoption of DR with a case study of Danish commercial greenhouses and use agent-based simulation to identify how the monetary costs affect the adoption rate of DR by commercial greenhouse growers.

This paper is organized as follows: first, the research background aims to give an understanding of this research; second, the simulation design is described to introduce the simulation logic; third, the case study is described, and the results are presented and discussed; last, a conclusion including the research findings is presented.

\section{RESEARCH BACKGROUND}

Smart grid is a modernized electrical grid allowing for twoway communication. Smart grid consists of a wide range of technologies including advanced sensors, energy storage, and smart meters. One of the most important technologies is smart meters which enable two-way communication [7]. Flexibility is the ability of electrical systems to maintain the balance between energy supply and demand. DR is voluntary changes in consumers' electricity usage patterns - in response to market signals [8]. It is possible to utilize consumer energy flexibility through DR by use of two-way communication.

DR provides the ability to reduce the use of peak load generation, electricity cost, and to improve system reliability [9]. DR programs aim to incentivize changes in the electricity consumption patterns in response to the varying electricity prices or incentivize payments to lower electricity consumption at times with high market prices [10]. There are two DR approaches called explicit- and implicit DR.

Explicit DR is a program that gives the end-users the possibility to compete in the wholesale market with producers, balancing and ancillary services. This is possible with services provided by aggregators or single large consumers. Aggregators trade aggregated load in the electricity markets, receive payment comparable with the generation, and consumers receive direct payment in the explicit DR $[10,11]$.

Digital Object Identifier (DOI):

http://dx.doi.org/10.18687/LACCEI2020.1.1.509

ISBN: 978-958-52071-4-1 ISSN: 2414-6390

18th LACCEI International Multi-Conference for Engineering, Education, and Technology: "Engineering, Integration, and Alliances for a Sustainable Development" "Hemispheric Cooperation for Competitiveness and Prosperity on a Knowledge-Based Economy", July 27-31, 2020, Virtual Edition. 
Implicit DR program refers to consumers being exposed to time-varying electricity prices that reflect electricity prices in different time periods. Consumers react to those price differences without commitment. These prices are agreed beforehand as part of their electricity supply contract. This program, therefore, does not allow consumers to participate alongside generation in the electricity markets $[10,11]$.

In Denmark, DR aggregation can only take place through suppliers, as independent aggregators are not allowed. The balancing programs are mainly designed for production and not consumption [11]. Therefore, consumers only have the opportunity to participate in the implicit DR program in Denmark. Hence, this paper chooses the implicit DR for the case study.

This paper investigates the decision-making process for adoption of smart energy solutions such as DR. A decisionmaking process consists, according to [12], of the following 7 steps: 1) identify the decision, 2) gather information, 3) identify alternatives, 4) weigh the evidence, 5) choose among alternatives, 6) take action, and 7) review your decision. By knowing the adoption behavior of consumers, the adoption of smart energy solutions can be studied using agent-based simulation. This model can then help solution providers to simulate decision alternatives- step 5 of the decision-making process, and to choose the right actions (step 6).

However, the agent-based model relies on detailed innovation adoption behavior of the consumers. Innovation adoption means that consumers make full use of the innovation.

The decision that has to be taken should encourage the adoption of smart energy solutions (step 1, identifying the decision). The adoption rate is the simulation factor which measures what decision is the best. The adoption rate is an important element for the investigation of the market reaction towards an innovation.

Adoption rate is defined by [13] as "The rate of adoption is the pace at which new technology is acquired and used by the public." This can be represented by the number of members of the society who start using new technology or innovation during a specific period of time. Hence, the decision alternative with the highest adoption rate will be used.

\section{SIMULATION DESIGN}

The agent-based simulation is used in this paper for studying the adoption of a smart energy solution. The agents in this paper consist of a population of commercial greenhouse growers in Denmark. The implicit DR program is chosen as a smart energy solution.
Agent-based simulation is one of the artificial intelligence methods which allows agents to behave as close to real-life as possible. The agents are designed to operate in a certain environment and have knowledge about how to behave and to react to different changes. This knowledge is fed into the agent logic through data (e.g. historical data for how an agent behaves to a specific change in the environment) [14].

The model is designed and developed in the software toolAnyLogic. AnyLogic is a single simulation software tool that supports three simulation modeling methods: system dynamics, discrete event, and agent-based modeling and allows you to create multi-method models [15].

The simulation logic is to check each simulation hour if any adoption has been taken and to stop the simulation when $50 \%$ of the population has adopted it (Fig. 1, green flowchart). The decision logic of the simulation is shown in the orange flow chart, in Fig. 1. There are many parameters determining the adoption rate. In this specific case, for simplicity, the decision is only the monetary benefits. The simulation uses a retrospective method which looks at the possible saving if the smart energy solution is adopted from day one in the simulation by use of the historical data. Hence, when the accumulated saving during the simulation time equals the cost of adopting the smart energy solution, the consumer adopts the innovation.

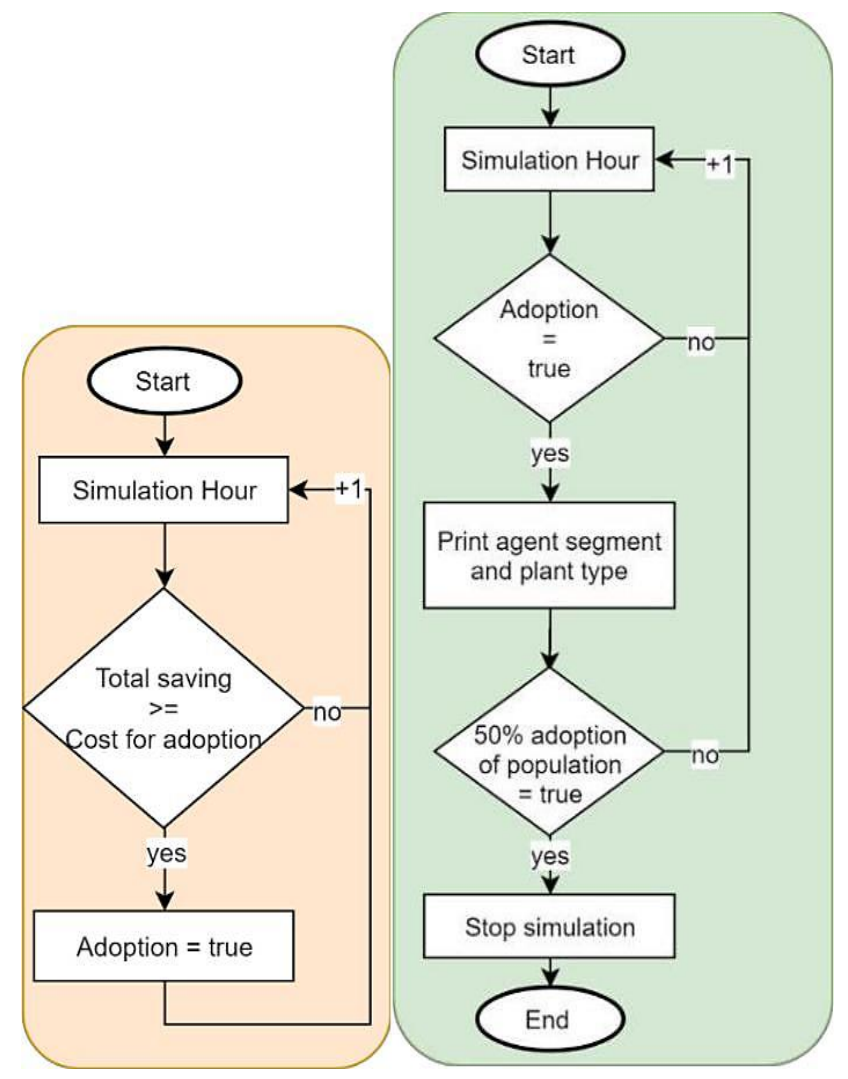

Fig. 1. Flow charts of model logic. [Orange: Decision logic] [Green: Simulation logic]. 

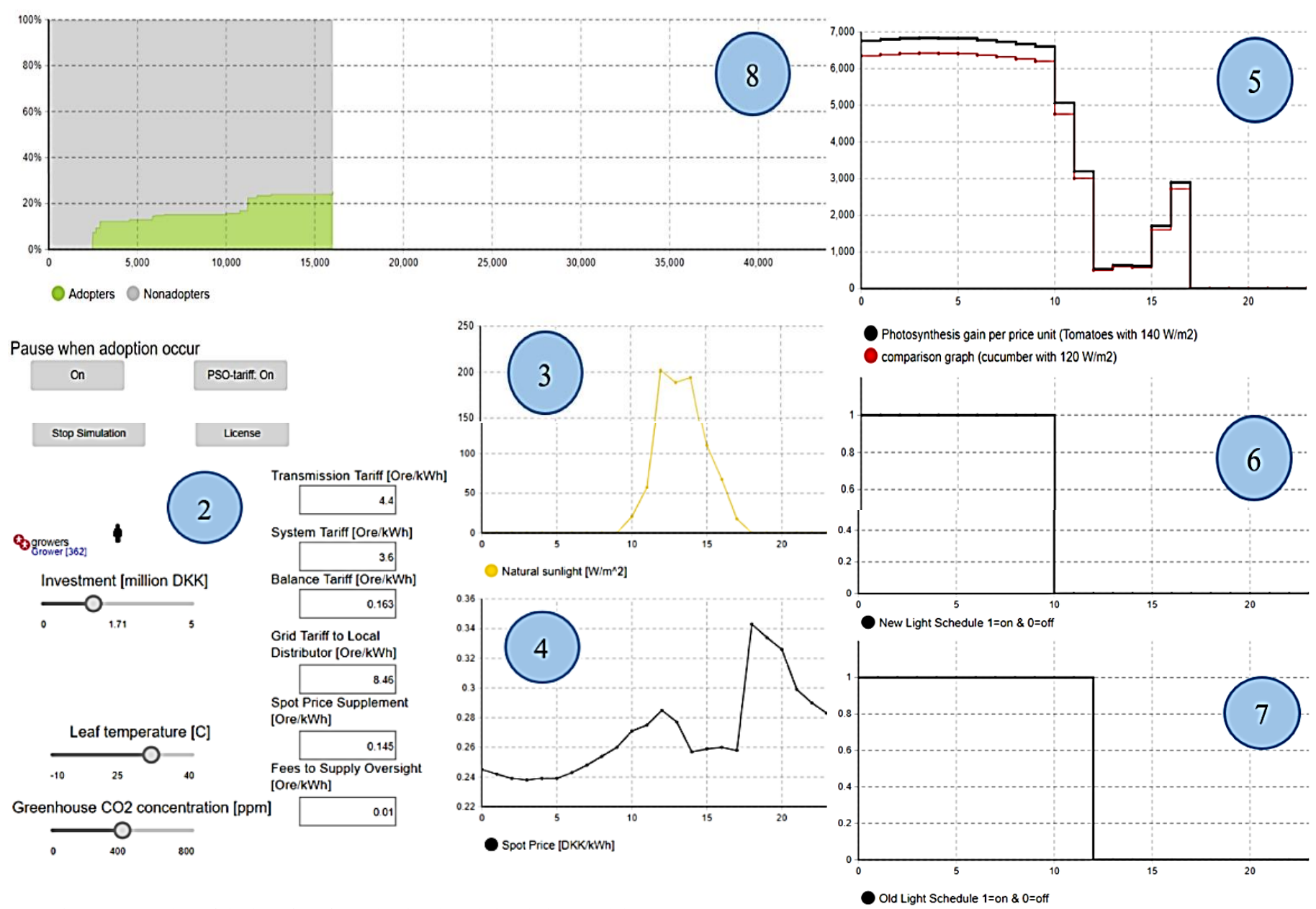

Fig. 2. Screenshot of the interface from the developed simulation model in AnyLogic.

This paper mainly investigates monetary benefits. Hence, important parameters are the adoption cost structure (e.g. onetime payment) and electricity price structure (e.g. subsidize DR programs by reducing electricity taxes).

Fig. 2 is a screenshot of the model developed in AnyLogic, and shows the running simulation:

1) Shows the information of the simulation time and also provides information about which type of agents adopt the solution, including the Return on Investment (ROI) time

2) Are the input parameters which allow changes to simulate a specific strategies

3) Represents a 24-hour forecast of the solar irradiations based on the historical data starting from 2015

4) Illustrates a 24-hour forecast of the electricity spot price also based on historical data from 2015 5) is a calculated forecast of the photosynthesis gain per spot price to determine when the plant obtains the highest photosynthesis at the lowest price.

This is found from the solar irradiation and spot price forecast. The photosynthesis gain as a function to the solar irradiation is non-linear. Hence, the extra gain added by supplementing the natural light by artificial light during the day may be low compared to the gain from artificial light alone during the night.

To illustrate this, a second graph is added with a different light consumption of 20 Watts per square meters. Comparing these two graphs, it can be seen that the differences in photosynthesis gain are high during the nights and low during the daytime. 6) shows the obtained artificial light schedule based on the hours with the highest photosynthesis gain per spot price where it is on at ' 1 ' and off at ' 0 '. The number of hours with artificial light depends on when the plant's required light sum (daily required amount of light) has been reached. Furthermore, the plant requirements for dark hours have to be considered too. 7) is the light schedule before implementing the smart energy solution which is used to find the achieved savings by adopting the new solution. The light schedule is based on information from a commercial greenhouse in Denmark. 8) is the adoption curve showing the percentage of the population who have adopted the solution. 


\section{CASE STUDY}

Commercial greenhouses in Denmark are chosen due to their large electricity consumption. In 2017, 436 commercial greenhouse growers consumed electricity corresponding to $0.7 \%$ of the total Danish consumption $[16,17] .75 \%$ of the consumed electricity is estimated to come from supplemental lighting [18]. These numbers show the potential of the electricity cost reduction if the commercial greenhouses participate in DR programs.

Commercial greenhouses produce plants, similar to other industries that produce goods. However, the production process depends on the types of plants. The plants are placed in different greenhouse areas based on the phases of the growing process [19]. This is due to the requirements of lighting and temperature change during the process.

Therefore, artificial lighting varies in installation and usage in different greenhouses. According to a plant expert, Prof. Carl-Otto Ottosen, Department of Food Science, Aarhus University, the installed artificial lighting power depends on the required light sum (the daily required light for a plant) for the specific plant species. Hence, a population of different commercial greenhouse growers is made based on their types of plants.

The population has been created based on data and information from the plant expert and 2017 nurseries statistics from Statistics Denmark (the national authority on Danish statistics) [20-21]. First, they are divided into the plant types: tomatoes, cucumbers, herbs, pot plants, and salad. These categories include information about the necessary installed artificial light power to meet the plant type's required light sums. Each of the categories is divided into 7 segments based on the greenhouse area. The population is implemented in the model by setting up in an excel sheet and imported to AnyLogic, which creates a population of agents.

The case study investigates at what time $50 \%$ of the population has adopted technologies for participating in an implicit DR program. This simulation will be used to find the maximum cost of 50\% adoption within 5 years by changing the investment parameter (see Fig. 2). The simulation starts in 2015 (corresponding to the historical data) and the adoption occurs when savings equal to the cost of adoption, and the adoption time equals to the ROI time. A ROI time of 5 years is estimated to be reasonable for medium-sized industries like commercial greenhouses. Furthermore, the simulation identifies the commercial greenhouse segments who adopt and at what rate.

Factors that distort the price of electricity: In order to make a meaningful comparison between different power generation technologies, an economic analysis should be based on open market costs without restrictions at each stage of the analysis. However, there are a number of factors that will distort costs and therefore affect price. Structural costs, costs associated with adapting a network to accommodate renewable generation, must include the energy cost of these technologies for any comparison to be fair. Likewise, externalities, costs to society associated with a wide range of environmental effects of power generation should also be included in a fully equitable analysis.

Their inclusion is likely to increase the cost of generation from fossil fuel powered plants. Subsidies exist in most corners of the world. Fuel subsidies, in particular, distort the wholesale price of electricity, while tariff subsidies will favor one group of consumers over another. The latter will also encourage excessive energy use. Tax regimes can also affect technologies differentially, distorting any comparison.

\section{RESULTS AND DISCUSSION}

The simulation output is shown in Fig. 3 and Table I. Fig. 3 illustrates the adoption curve which predicts the adoption rate based on the model setup. The information behind the curve can be found in Table I. Table I shows the type of commercial greenhouses who have adopted the solution and at what time. From the graph and table, it can be found that $50 \%$ of the adoption happens after 4 years, 10 months, and 19 days.

This adoption is for a one-time payment cost structure with a maximum adoption cost of 1.765 million DKK $(€$ 0.236 million) for each consumer. It means if the adoption cost equals to or is less than 1.765 million DKK per commercial greenhouse, $50 \%$ of the Danish commercial greenhouses will adopt this solution within 5 years under the current Danish electricity cost structure.

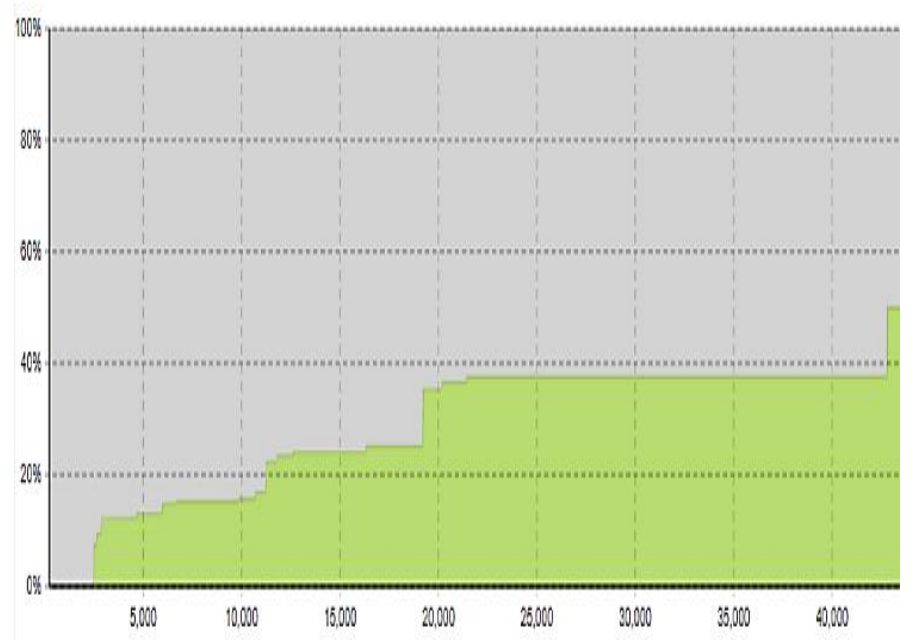

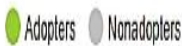

Fig. 3. Adoption curve for commercial greenhouses' adoption of DR. [Xaxis: Hours] [Y-axis: Adoption percentage of the population] 
Furthermore, the simulation shows (in TABLE I) that the commercial greenhouses who adopt first are the ones that produce either pot plants, tomatoes, cucumbers or herbs, and all with an area of more than $20,000 \mathrm{~m}^{2}$. These results suggest that if the monetary cost for adoption is more than DKK 1.765 million it is necessary to incentivize commercial greenhouses in other ways to reach a $50 \%$ adoption rate of 5 years.

TABLE I. ADOPTING AGENTS' TYPE AND RATE

\begin{tabular}{|l|c|c|c|c|}
\hline Plant type & $\begin{array}{c}\text { Grower } \\
\text { segment } \\
{\left[\boldsymbol{m}^{2}\right]}\end{array}$ & $\begin{array}{c}\text { ROI time: } \\
\text { years }\end{array}$ & $\begin{array}{c}\text { ROI time: } \\
\text { months }\end{array}$ & $\begin{array}{c}\text { ROI time: } \\
\text { days }\end{array}$ \\
\hline Pot plants & $>20,000$ & 0 & 3 & 14 \\
\hline Tomatoes & $>20,000$ & 0 & 3 & 20 \\
\hline Cucumber & $>20,000$ & 0 & 4 & 1 \\
\hline Herbs & $>20,000$ & 0 & 6 & 13 \\
\hline Pot plants & $15,000-19,999$ & 0 & 8 & 6 \\
\hline Cucumber & $10,000-14,999$ & 1 & 2 & 22 \\
\hline Pot plants & $10,000-14,999$ & 1 & 3 & 13 \\
\hline Herbs & $10,000-14,999$ & 1 & 4 & 6 \\
\hline Tomatoes & $5,000-9,999$ & 1 & 10 & 10 \\
\hline Pot plants & $5,000-9,999$ & 2 & 2 & 11 \\
\hline Cucumber & $5,000-9,999$ & 2 & 3 & 20 \\
\hline Herbs & $5,000-9,999$ & 2 & 5 & 11 \\
\hline Pot plants & $2,000-4,999$ & 4 & 10 & 19 \\
\hline
\end{tabular}

The last two technologies, solar cells and fuel cells, are new technologies that are still under development in the simulation. The prices of both can be expected to drop relative to their competitors as the technology matures further. Gas turbines, on the other hand, are based on mature technology and the scope for further price reduction is small. However, all three are technologies that allow you to buy pre-built 'ready-to-use' modules ready for installation.
Gas-fired combined cycle plants are modular in nature, and many of the components are brought to the site ready to build. This helps them to be cheap to build. In contrast, much of a nuclear power plant must be built on site. This implies considerable material and labor costs and these costs are part of the reason why nuclear energy. Power plants are expensive (there are others). A coal-fired plant, such as a nuclear power plant, involves significant construction on site and this again increases the cost.

There is also a fundamental difference between, on the one hand, nuclear power plants and those that run on fossil fuels and, on the other hand, those that are based on renewable energy sources. While the former have fuel costs, the latter have none. This does not affect your capital costs, but it does make a huge difference when calculating the cost of electricity produced by each plant. This is reflected in the leveled cost (see below).

\section{CONCLUSION}

This paper investigates how the monetary factor affects the adoption of smart energy solutions. The agent-based simulation in this paper mainly helps strategy decision support. The paper presents how agent-based simulation can be used in the decision-making for adoption of smart energy solutions.

The case study demonstrates that agent-based simulation works well as a tool for studying decision-making behavior. The simulation result estimates that it is possible to reach an adoption rate of $50 \%$ under 5 years with a maximum adoption cost of 1.765 million DKK with the current electricity price structure. However, if a higher adoption cost applies, regulation is needed to incentivize the consumers to adopt new solutions with the adoption rate of $50 \%$ under 5 years.

In fact, in addition to monetary factors, many other factors such as social, compatibility and complexity factors affect the adoption of an innovation. Therefore, a model that considers more factors than used is recommended for future research. Furthermore, this document suggests future research to identify innovators, early adopters, and early majorities on the adoption curve. 


\section{REFERENCES}

[1] United_Nations_Treaty_Collection. "7.d Paris Agreement." https://treaties.un.org/Pages/ViewDetails.aspx?src=TREATY \&mtdsg_no=XXVII-7-d\&chapter=27\&clang=_en $($ accessed $10 / 13 / 2018)$.

[2] United_Nations_Climate_Change. "The Paris Agreement." https://unfccc.int/process-and-meetings/the-paris-agreement/theparis-agreement (accessed 10/13/2018).

[3] Danish Energy Agency. "Energiaftale - af 29. juni 2018." https://efkm.dk/media/12222/energiaftale2018.pdf.

[4] U. a. C. Danish_Ministry_of_Energy. "The climate initiative in Denmark." https://en.efkm.dk/climate-and-weather/the-climateinitiative-in-denmark/ .

[5] E. a. B. Danish_Ministry_of_Climate. "Smart Grid Strategy." https://ens.dk/sites/ens.dk/files/Globalcooperation/smart_grid_ strategy_eng.pdf .

[6] R. Reinhardt, N. Hietschold, and S. Gurtner, "Overcoming consumer resistance to innovations - an analysis of adoption triggers," 2017.

[7] K. T. Raimi and A. R. Carrico, "Understanding and beliefs about smart energy technology," Energy Research \& Social

Science, vol. 12, pp. 68-74, 2016, doi: 10.1016/j.erss.2015.12.018.

[8] Z. Ma, J. D. Billanes, and B. N. Jørgensen, "Aggregation Potentials for Buildings-Business Models of Demand Response and Virtual Power Plants," energies, pp. 1-19, 2017. [Online]. Available: https://www.mdpi.com/1996-1073/10/10/1646.

[9] M. Minou, G. D. Stamoulis, G. Thanos, and V. Chandan, "Incentives and targeting policies for automated demand response contracts. ," In Proceedings of the 2015 IEEE International Conference on Smart Grid Communications (SmartGridComm), pp. 557-562, 2-5 November2015. [Online]. Available: http://nes.aueb.gr/publications/SMARTGRIDCOM_camera_r eady_final_v1.pdf.

[10] P. Bertoldi, P. Zancanella, and B. Boza-Kiss, "Demand Response status in EU Member States," EUR 27998 EN, pp. 1-140, 2016, doi: $10.2790 / 962868$.

[11] SEDC, "Mapping Demand Response in Europe Today 2015," Smart Energy Demand Coalation (SEDC), pp. 1-187, 2015.

[12] University of Massachusetts Darthmouth. "Decision-making process." https://www.umassd.edu/fycm/decisionmaking/process/ (accessed June 07, 2019).

[13] W. Kenton and Investopedia. "Rate of Adoption." Investopedia. https://www.investopedia.com/terms/r/rate-of-adoption.asp (accessed 04/11/2019).

[14] A. Wodecki, Artificial Intelligence In Value Creation - Improving Competitive Advantage. 2019, p. 340.

[15] I. Grigoryev, "Anylogic in three days," 2016.

[16] Danmarks Statistik. "Energiforbruget i væksthuse halveret på 15 år." https://www.dst.dk/da/Statistik/nyt/NytHtml?cid=25153 (accessed 04/09/2019.

[17] Energistyrelsen, "Energistatistik 2017," pp. 1-58, 2017. [Online]. Available:

https://ens.dk/sites/ens.dk/files/Statistik/pub2017dk.pdf.

[18] J. C. Sørensen, K. H. Kjaer, C.-O. Ottosen, and B. N. Jørgensen, "DynaGrow - Multi-Objective Optimization for Energy Cost-efficient Control of Supplemental Light in Greenhouses," 8th International Joint Conference on Computational Intelligence (IJCCI 2016), vol. 1: ECTA, pp. 41-48, 2016.

[19] J. Korsgaard, "Energy Flexible Industry 4.0," pp. 16-18, 2018.

[20] Statistics Denmark, "Tabeller til Energistyrelsen og Dansk Gartneri, landbrugs- og gartneritællingen 2018, tal om væksthuse " 2018.

[21] E. M. Rogers, Diffusion of Innovations, Fifth ed. Free Press, 2003, p. 551. 